\title{
High Grade B-Cell Lymphoma with MYC and BCL2 and/or BCL6 Rearrangements
}

National Cancer Institute

\section{Source}

National Cancer Institute. High Grade B-Cell Lymphoma with MYC and BCL2 and/or BCL6

Rearrangements. NCl Thesaurus. Code C138195.

A rare B-cell non-Hodgkin lymphoma that is characterized by the abnormal

rearrangement of MYC gene, BCL2 gene, and/or BCL6 gene. Patients with this type of lymphoma usually respond poorly to standard treatments and have a poor prognosis. 